\title{
How to Control Powder Alignment to Maximize Functionality and Performance of Color Cosmetics and Sunscreen
}

\author{
Shoji Takekawa ${ }^{1 *}$, Miwa Ohara², Taisuke Banno', and Kouichi Asakura ${ }^{1 *}$ \\ ${ }^{1}$ Department of Applied Chemistry, Faculty of Science and Technology, Keio University, 3-14-1 Hiyoshi, Kohoku-ku, Yokohama 223-8522, JAPAN \\ ${ }^{2}$ Research and Development, Miyoshi America, Inc. 110 Louisa Viens Drive, Dayville, CT 06241, U.S.A.
}

\begin{abstract}
Control of powder alignment is essential for maximizing the functionality of color cosmetics and sunscreens. Various surface treatments were applied to nanosized titanium dioxide to modify their surface characteristics. Such modifications can be used to control the behavior of dispersions in cosmetics, enabling them to align uniformly. The powders were mixed with solvents and applied to a cellulose triacetate film. The features of powder alignment on the film were evaluated using several approaches. When the type of surface treatment changed by varying the weight ratio, there was no significant correlation between its alignment and treatment. However, when we focused on the pseudo-HLB each treated pigment, their alignments were correlated. It was confirmed that the powders subjected to the appropriate surface treatment combinations from the pseudo-HLB standpoint made it possible to align uniformly and create a smooth coating film. As a result, it has a high UV-shielding ability. The surface-treated powders in this study were found to change the UV shielding ability and surface roughness of the layer formed when they were formed by spreading the sample powder dispersion and drying of the film. It was suggested that the pseudoHLB, which is calculated based on the chemical structure after the surface treatment process, is useful for choosing the optimum surface treatment to create a uniformly aligned pigment layer.
\end{abstract}

Key words: color cosmetics, surface treatment, UV protection, dynamic interface, skin barrier

\section{Introduction}

Titanium dioxide and iron oxides are used as functional powders in color cosmetics and sunscreen formulas, along with other compounds such as surfactants, emollients, and preservatives ${ }^{1}$. The development of functional powders that can form a uniform layer on the skin is critical to their functionality in cosmetics and sunscreens to attain two major benefits, i.e. esthetics and protection ${ }^{2}$. Our skin tends to be exposed to harmful environments, including various types of light, such as UV and blue light, and environmental stimuli such as allergens and pollutants. However, the preparation of color cosmetics and sunscreen formulas that can form a uniform applied layer on the skin is challenging ${ }^{2}$ because they contain volatile solvents such as water, cyclopentasiloxane, and branched hydrocarbons. The evaporation of volatile liquids from their thin layers usually take place in a far-from-equilibrium condition in which Marangoni convection causes a spatial distribution of the content the content ${ }^{3-9)}$, which critically influences the structure of the cosmetic layer formed on the $\operatorname{skin}^{10)}$. Powder migration is significantly influenced by the viscosity and volatility of the liquid phases, and the spatial partitioning behavior of powders in hydrophilic, hydrophobic, or boundary regions can be observed ${ }^{11}$. To obtain a consistently uniform application on the skin, after applying a multicomponent formula, trial-and-error experiments based on the formulator's hands-on experience are usually required. For example, attempts were made to change the order of addition of chemicals, such as a neutralized agent, to maintain the low viscosity of the batch until all components were added; in addition, mixing conditions such as the shapes of homogenizing mixers, propellers, paddletype, and mills were changed for each required shear strength and controlling the temperature that affects the conditions of volatile materials, fragrances, and preservatives $^{12)}$.

In this study, we focused on the surface properties of functional powders and their influence on the ability of the

\footnotetext{
*Correspondence to: Kouichi Asakura, Department of Applied Chemistry, Faculty of Science and Technology, Keio University, 3-14-1 Hiyoshi, Kohoku-ku, Yokohama 223-8522, JAPAN

E-mail: asakura@applc.keio.ac.jp

Accepted April 10, 2021 (received for review March 12, 2021)
}

Journal of Oleo Science ISSN 1345-8957 print / ISSN 1347-3352 online

http://www.jstage.jst.go.jp/browse/jos/ http://mc.manusriptcentral.com/jjocs 


\section{S. Takekawa, M. Ohara, T. Banno et al.}

powders to form a uniform layer on application. Three types of surface treatments were conducted on attenuation-grade titanium dioxide powders to alter their functionalities. They were milled and ground in cosmetic oils to prepare dispersion samples, and the dispersion was applied to a cellulose triacetate film. Surface uniformity, UV shielding ability, and surface gloss were evaluated for the sample layer after the completion of the evaporation of the cosmetic oils. The relationship between the surface treatments and the structures and properties of the applied sample layer were analyzed. In addition, we introduced the concept of pseudo-HLB, which is calculated from the HLB of the surface treatment agent based on Griffin's equation for characterizing the influence of surface treatment on the uniformity of the applied sample layer.

\section{Materials and Methods}

\subsection{Surface treatment}

Nanosized titanium dioxide powder (STR-40C) was purchased from Sakai Chemical Industry Co., Ltd. Different surface treatments were applied to this nano-sized titanium dioxide powder to modify its surface characteristics (Table 1). The treatment agents were triethoxy (octyl) silane (Wacker Chemie AG), TS, disodium N-(1-oxooctadecyl)L-glutamate (Ajinomoto Co., Inc.), DG, and potassium myristate(NOF corporation), PM. Treatment using TS conventional $^{13)}$ and involves hydrolysis, generating three silanol moieties that adsorb on the hydroxyl sites of the titanium dioxide surface via hydrogen bonding. This was followed by a condensation reaction(dehydration reaction) to form

Table 1 Summary of surface treatments on the test samples of the nanosized titanium dioxide powders.

\begin{tabular}{cccc}
\hline & \multicolumn{3}{c}{ Content of surface } \\
Sample & \multicolumn{2}{c}{ treating agents (\%) } \\
& TS & DG & PM \\
\hline Control & & & \\
1 & 3.00 & & \\
2 & & 3.00 & \\
3 & & & 3.00 \\
4 & 1.50 & 1.50 & \\
5 & & 1.50 & 1.50 \\
6 & 1.50 & & 1.50 \\
7 & 1.00 & 1.00 & 1.00 \\
\hline
\end{tabular}

siloxane bonds. Both DG and PS treatments form chemical bonds with multivalent metal ions ${ }^{14)}$. Multiple treatment (TS/DG, TS/PM, or TS/DG/PM treatment) samples were prepared by using $D G$ or/and $P M$ treatment as the first process followed by the above TS treatment.

\subsection{Preparation of dispersions and their application to form layers}

The liquid used for the preparation of the dispersions was a mixed solvent of cyclopentadecamethylsiloxane (Shin-Etsu Chemical Co., Ltd.) and isododecane (Elementis plc), in a 1:1 ratio by weight. The pre-dispersion was prepared by dispersing the treated titanium dioxide powder in a mixed solvent at $2000 \mathrm{rpm}$ for $10 \mathrm{~min}$ using a disperser (ROBOMIX, PRIMIX Corporation). The weight ratio of the powder to the mixed solvent was 1:3. The pre-dispersion $(140 \mathrm{~mL}$ ) was mixed with $500 \mathrm{~g}$ of 1-mm diameter zirconia beads in the grinding pot of a bead mill(EASY NANO RMB, AIMEX CO., LTD) and ground at $1405 \mathrm{rpm}$ for $45 \mathrm{~min}$. The dispersion was then mixed with an equal volume of mixed solvent. The diluted dispersion thus obtained was applied using an applicator(Wire-wound rod 0.2 mils, BYK USA Inc.) on cellulose triacetate film (PBZ13001, Idemitsu Technofine Co Ltd.). The properties of the aligned powder films were characterized after the solvent evaporated completely.

\subsection{Characterization of properties of the applied layer}

The UV shielding capability of the applied and dried sample layers was characterized using an SPF analyzer (UV-2000, Labsphere Inc.). The surface structure was analyzed by gloss measurement at $45^{\circ}$ using a micro-gloss glossmeter (micro-TRI-gloss, BYK USA Inc.). Scanning electron microscopy (SEM) (JSM-6010LA, JEOL Ltd.) and laser microscopy (LEXT OLS4100, OLYMPUS CORPORATION) observations were also carried out to analyze the surface structure.

\section{Results}

The UV shielding ability of the hydrophobic titanium dioxide powder layer, which was treated using three types of agents and their combinations, determined by an SPF analyzer, is shown in Fig. 1. Although the intensity of UV light passing through the sample layer did not decline due to UV absorption, the SPF analyzer showed a degree of declining UV intensity as the UV absorbance. To make the rheological texture of each dispersion identical, their viscosity was adjusted to $5.0 \times 10^{-2} \mathrm{~Pa} \cdot \mathrm{s}$ by ensuring that the powder content in the dispersion is held constant at $12.5 \%$. In addition, the same applicator was used for every sample to ensure that the thickness of the sample layer was constant. While the applied layer of untreated titanium 


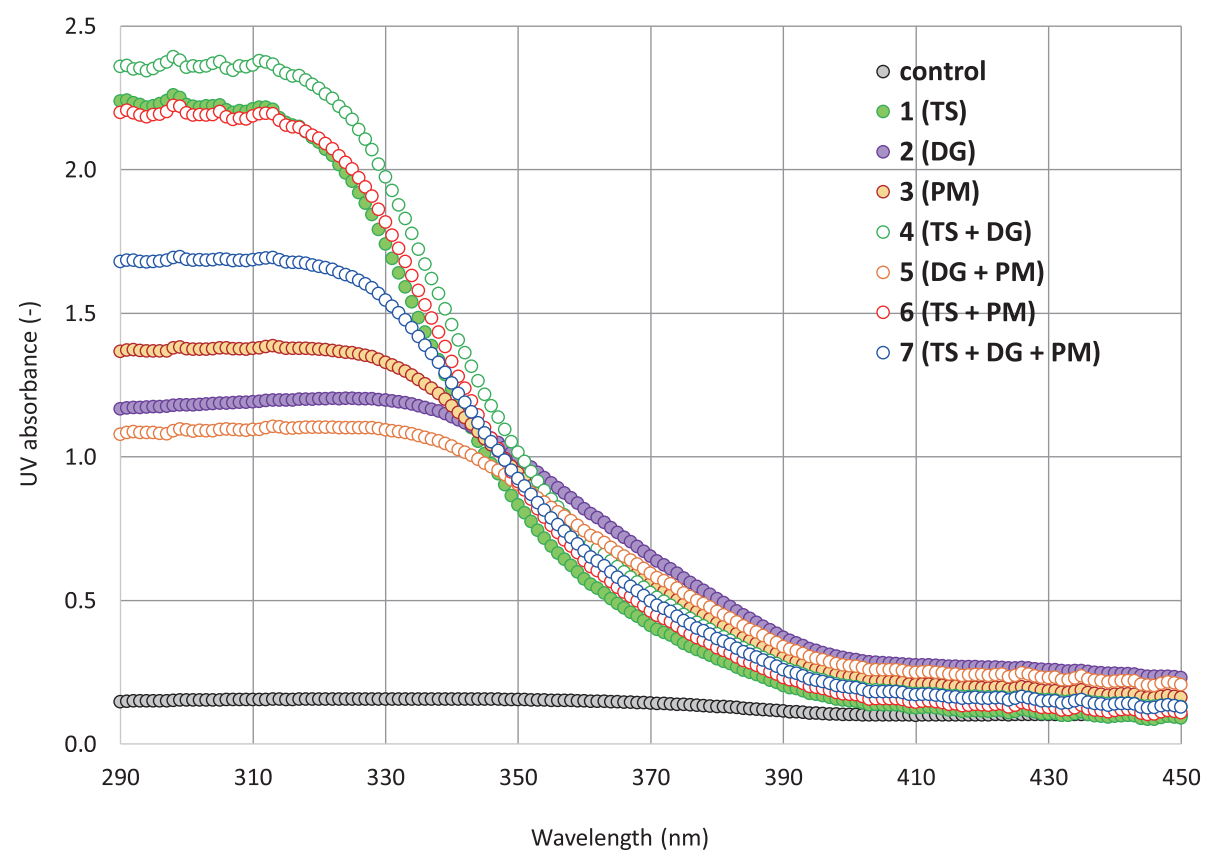

Fig. 1 UV absorbance of the sample layer prepared by applying the oil dispersion of surface treated and untreated powders. Note: "Control" means that the suspension contained no surface treatment powder. Sample 1 through 7 are listed in Table 1.

dioxide powder layer scarcely shielded the UV light, a clear effect was found for the surface-treated titanium dioxide powder, which enhanced the UV shielding ability of the applied layer (Fig. 1). The applied layer on the TS treated samples tended to exhibit higher UV shielding properties, and sample 4 exhibited the highest ability, followed by samples 1,6, and 7. Moderate enhancements of UV shielding properties were observed for the DG and PM treatments.

As summarized in Figs. 2 and 3, SEM and gloss meter observations revealed that the conditions of particle alignment in the layers of samples 1, 4, 6, and 7 were very uniform and had a smooth surface. The SEM images of samples 1, 4, 6, and 7 indicated that their surfaces were smoother than those of the other samples. In addition, the gloss numbers of these sample layers were also higher than those of the others, indicating that a less textured surface was generated.

Laser microscope observations were employed to characterize the bumpiness of the layer. The surface roughness of samples 1, 4, 6, and 7, which are represented by Sa (arithmetical mean deviation of the assessed profile) and $\mathrm{Sq}$ (root mean square height), were found to be smaller than those of the other samples (Fig. 4). To quantitatively evaluate the UV shielding ability of each sample layer, the integrated UV absorbance, a measure of the UV shielding ability, was calculated as the sum of the UV absorbance at each nanometer from $290 \mathrm{~nm}$ to $450 \mathrm{~nm}$. It showed that a higher UV shielding ability was realized for the sample layers with lower Sa values (Fig. 5). The results clearly showed that the uniformity of the layer affects the UV shielding ability, and the uniformity in turn depends on the type of surface treatment conducted on the nano-sized titanium dioxide powder. A similar tendency was observed for the relationship between the integrated UV absorbance and $45^{\circ}$ gloss. A higher UV shielding ability was realized for the sample layer with a higher value of $45^{\circ}$ gloss.

\section{Discussion}

In our earlier studies, it was confirmed that the UV absorbance of a sunscreen layer decreased with layer roughness ${ }^{15,16)}$. As shown in Figs. 5 and 6 , the high gloss and low Sa values, which demonstrate high uniformity in the alignment of titanium dioxide particles, delivered better UV shielding ability. The distribution of organic UV absorbers that are contained in sunscreens is influenced by the dynamic interface caused by the difference in the evaporation rate of the solvent ${ }^{17)}$. The results of this study suggest that the alignment of the treated and untreated titanium dioxide powders formed during the evaporation of the mixed solvent, cyclopentasiloxane and isododecane, was influenced by the dynamic interface caused by the difference in the evaporation rate of each solvent. Thus, it is very important to minimize the influence of the dynamic interface to obtain the optimum UV shielding ability.

Surface treatments were found to be effective control parameters for ensuring uniform alignment of the powders. Surface treatment involves the reaction of various sub- 

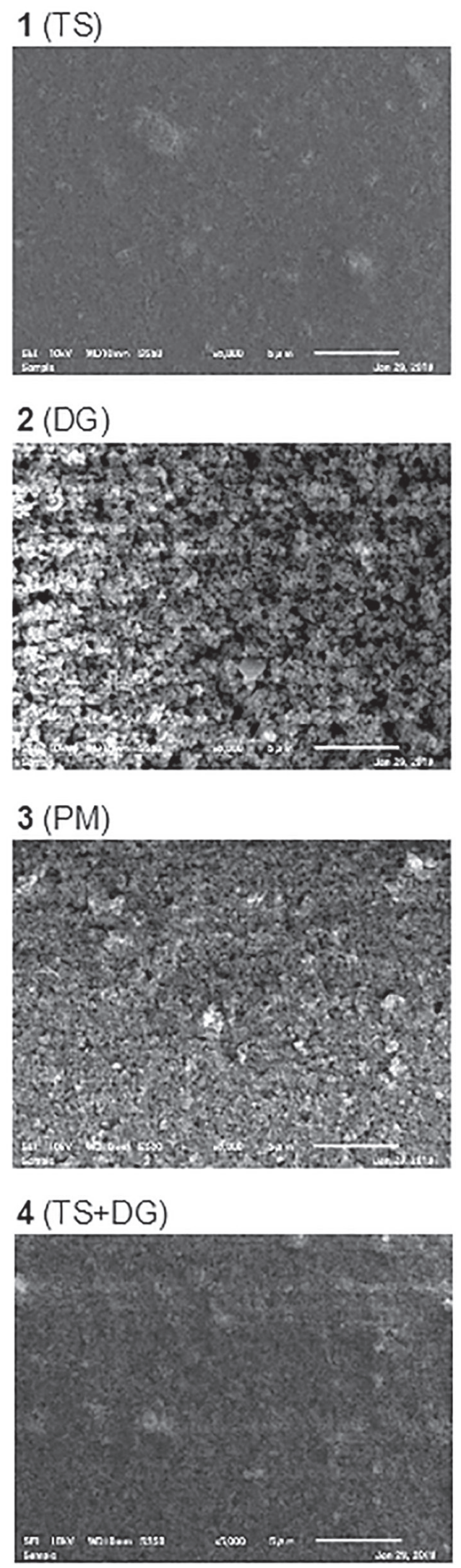

Fig. $2 \operatorname{SEM}(10 \mathrm{kV}$ x5,000) images of the sample layer prepared by applying the oil dispersion of powders. (Scale bar: $5 \mu \mathrm{m})$.

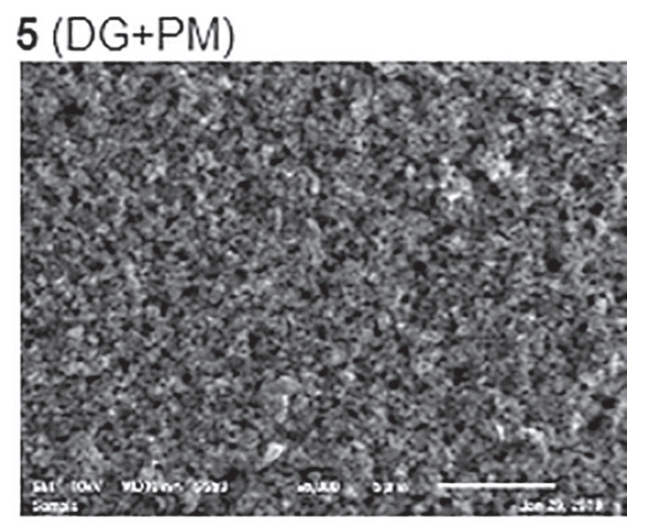

\section{6 (TS+PM)}

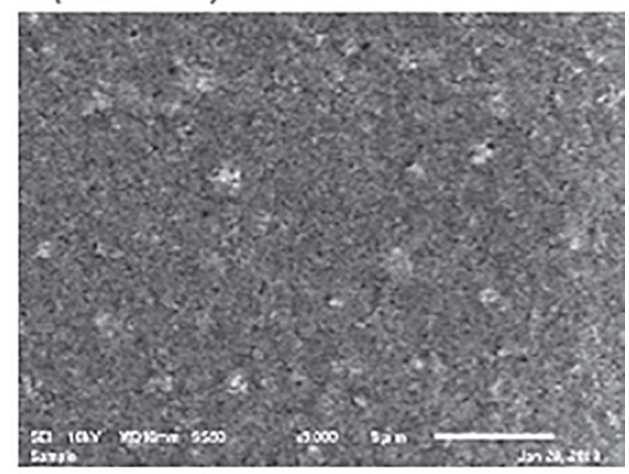

7 (TS+DG+PM)

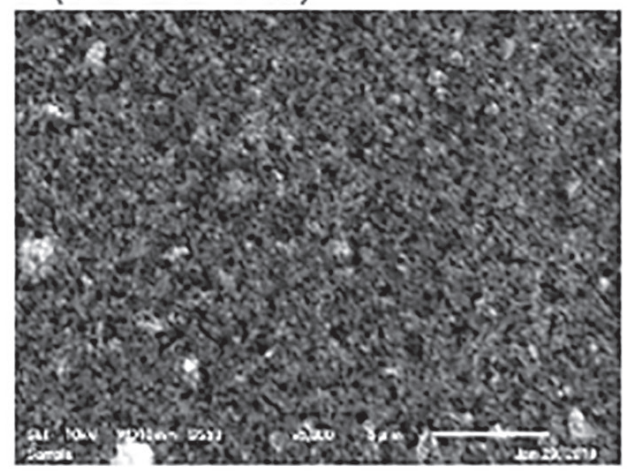



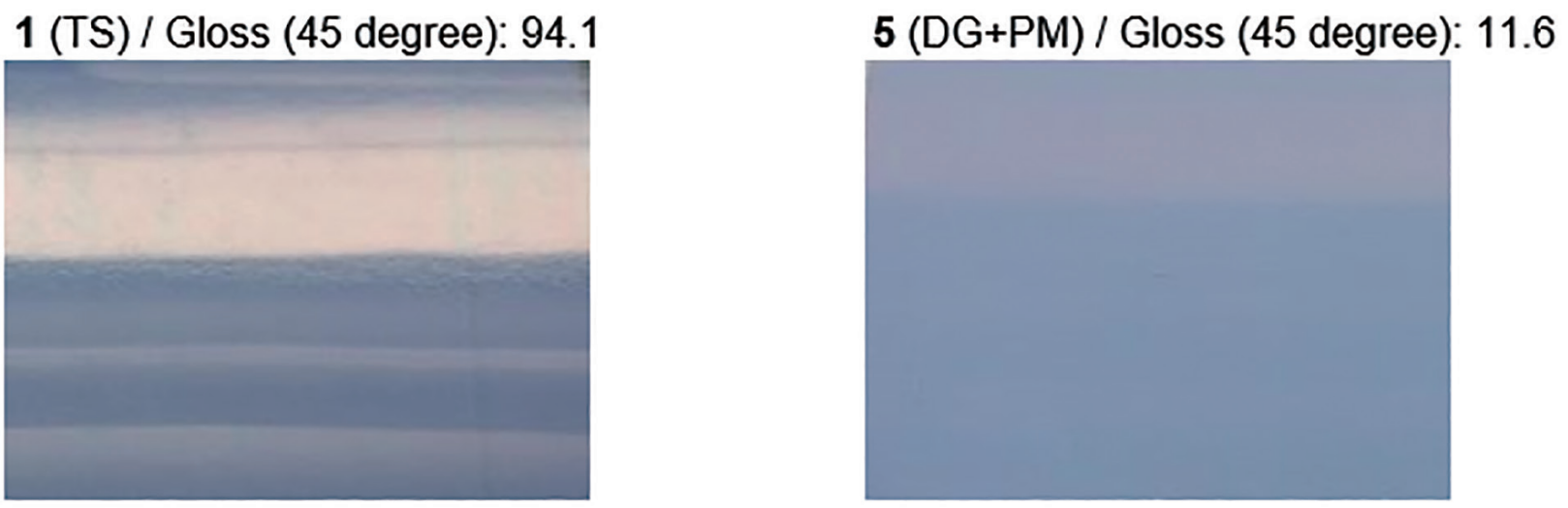

2 (DG) / Gloss (45 degree): 6.2
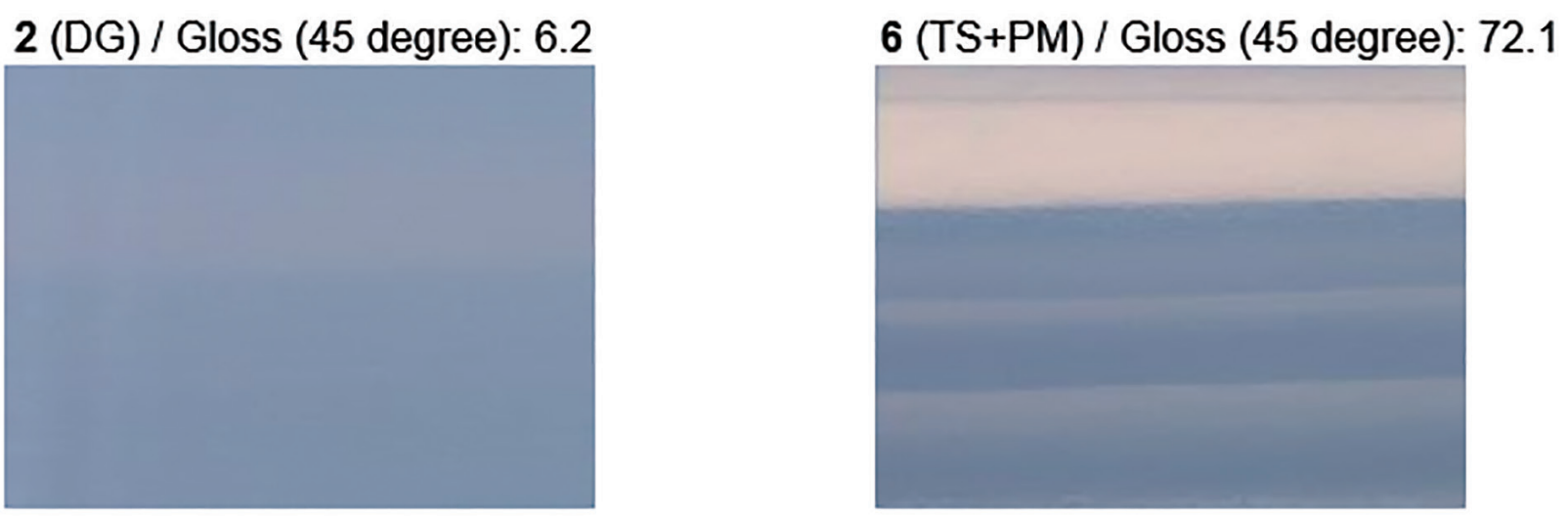

3 (PM) / Gloss (45 degree): 31.8

7 (TS+DG+PM) / Gloss (45 degree): 49.5
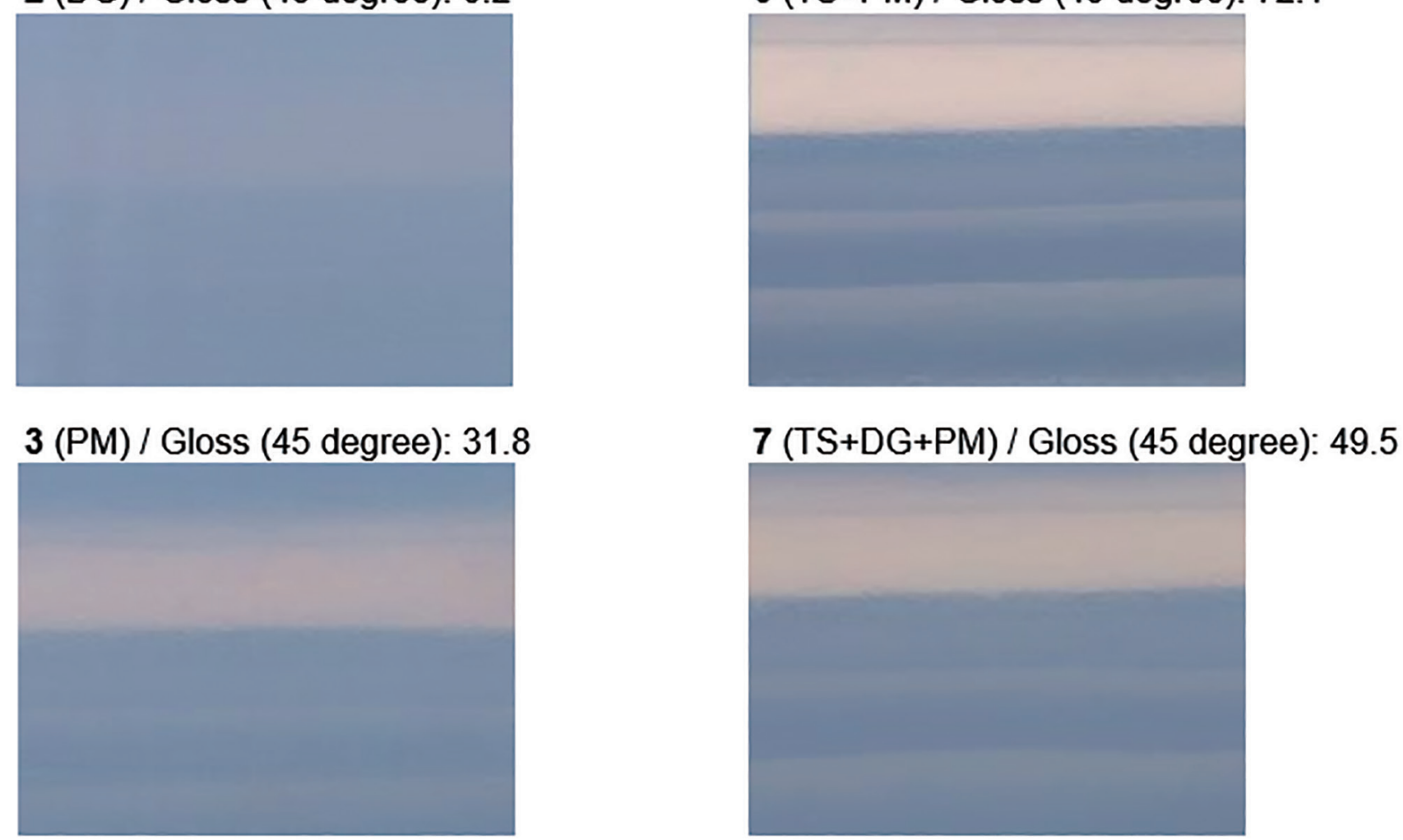

4 (TS+DG) / Gloss (45 degree): 46.2

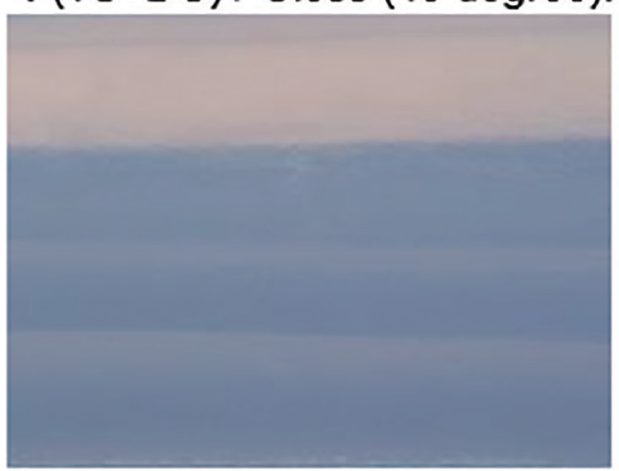

Fig. 3 Picture images (40 mm on the side) of the sample layer prepared by applying the oil dispersion and each 45 degree gloss. 


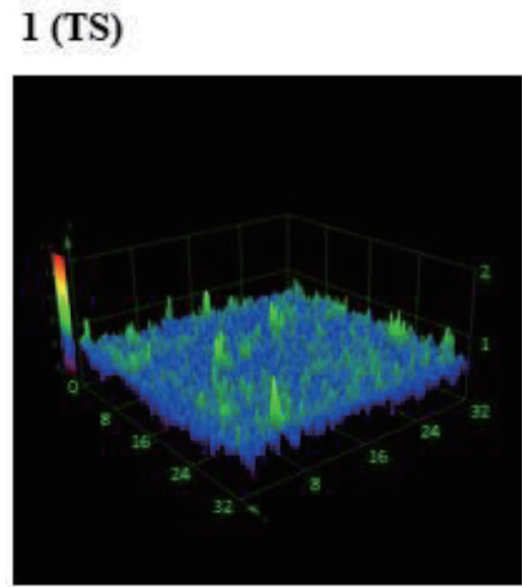

$S a=0.063 \mu \mathrm{m}, S q=0.086 \mu \mathrm{m}$

2 (DG)

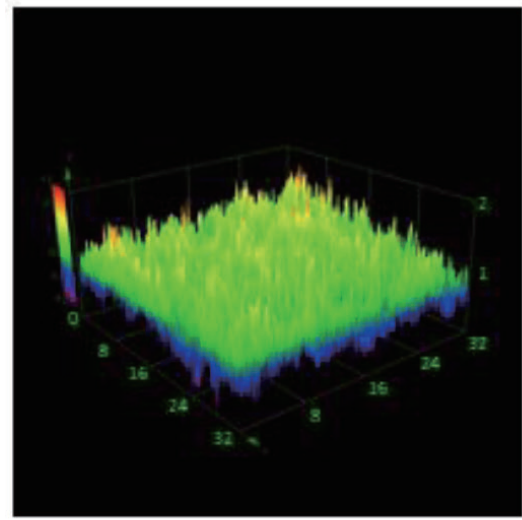

$S a=0.152 \mu \mathrm{m}, S q=0.192 \mu \mathrm{m}$

$3(\mathrm{PM})$

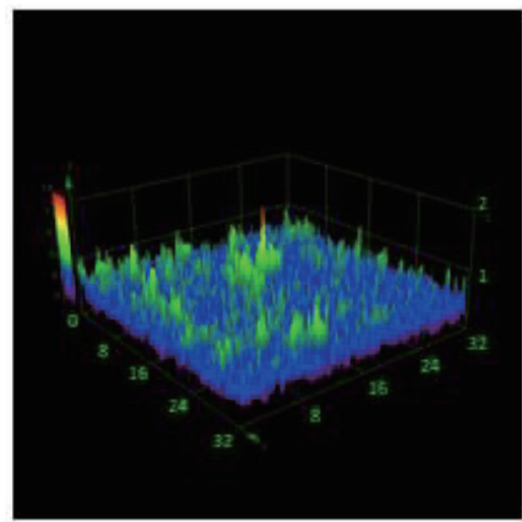

$S a=0.095 \mu \mathrm{m}, S q=0.121 \mu \mathrm{m}$
4 (TS+DG)

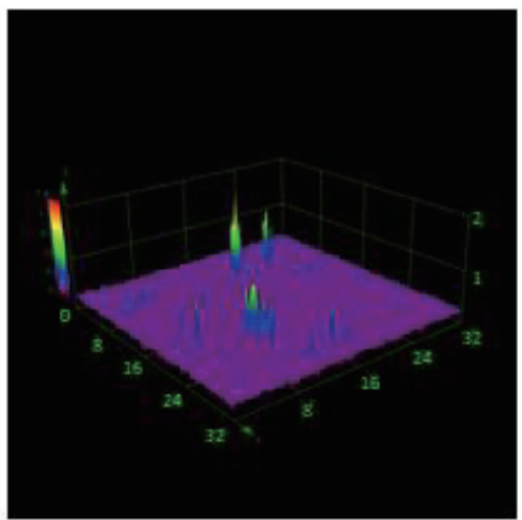

$S a=0.019 \mu \mathrm{m}, S q=0.037 \mu \mathrm{m}$

$$
5(\mathrm{DG}+\mathrm{PM})
$$

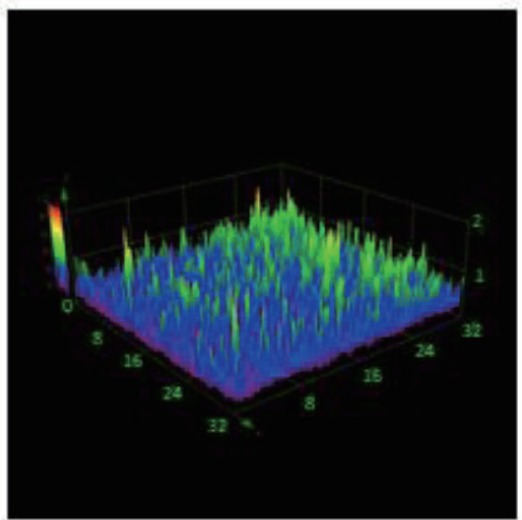

$S a=0.084 \mu \mathrm{m}, S q=0.111 \mu \mathrm{m}$ $6(\mathrm{TS}+\mathrm{PM})$

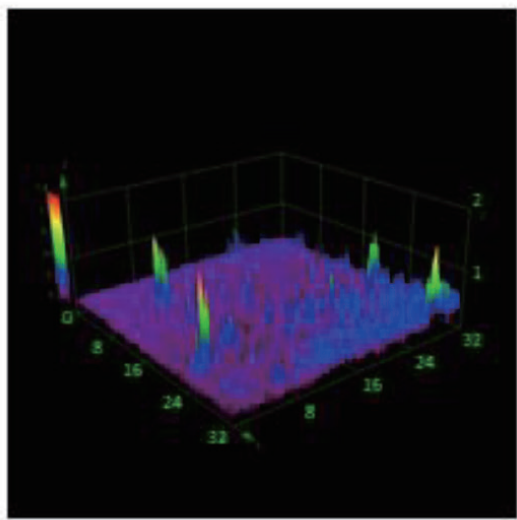

$S a=0.054 \mu \mathrm{m}, S q=0.075 \mu \mathrm{m}$

\section{7 (TS+DG+PM)}

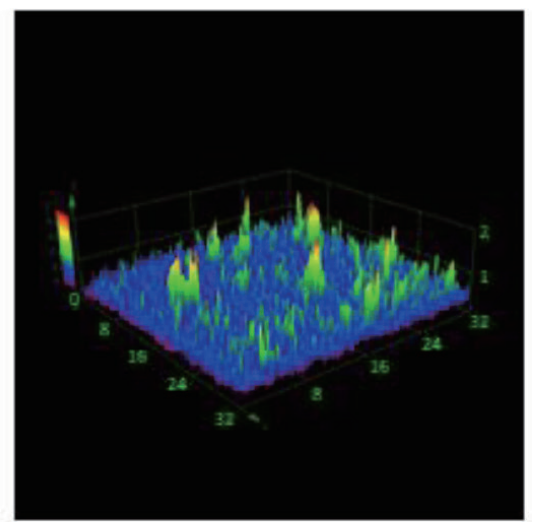

$S a=0.074 \mu \mathrm{m}, S q=0.099 \mu \mathrm{m}$

\section{Control}

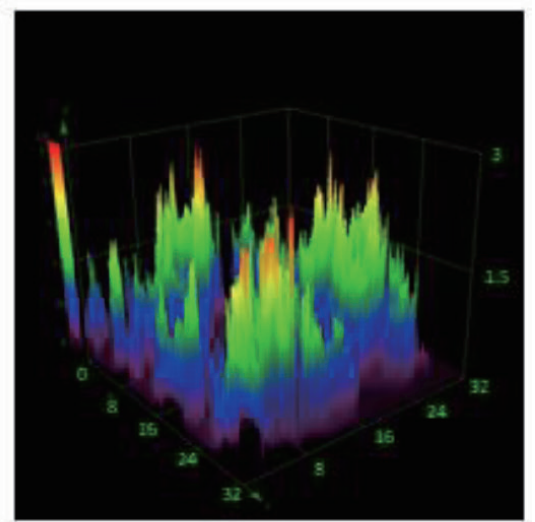

$S a=0.369 \mu \mathrm{m}, S q=0.463 \mu \mathrm{m}$

Fig. 4 Laser microscope images of the sample layer prepared by applying the oil dispersion of powders and the values of Sa and Sq. (Scale unit: $\mu \mathrm{m}$ ). 


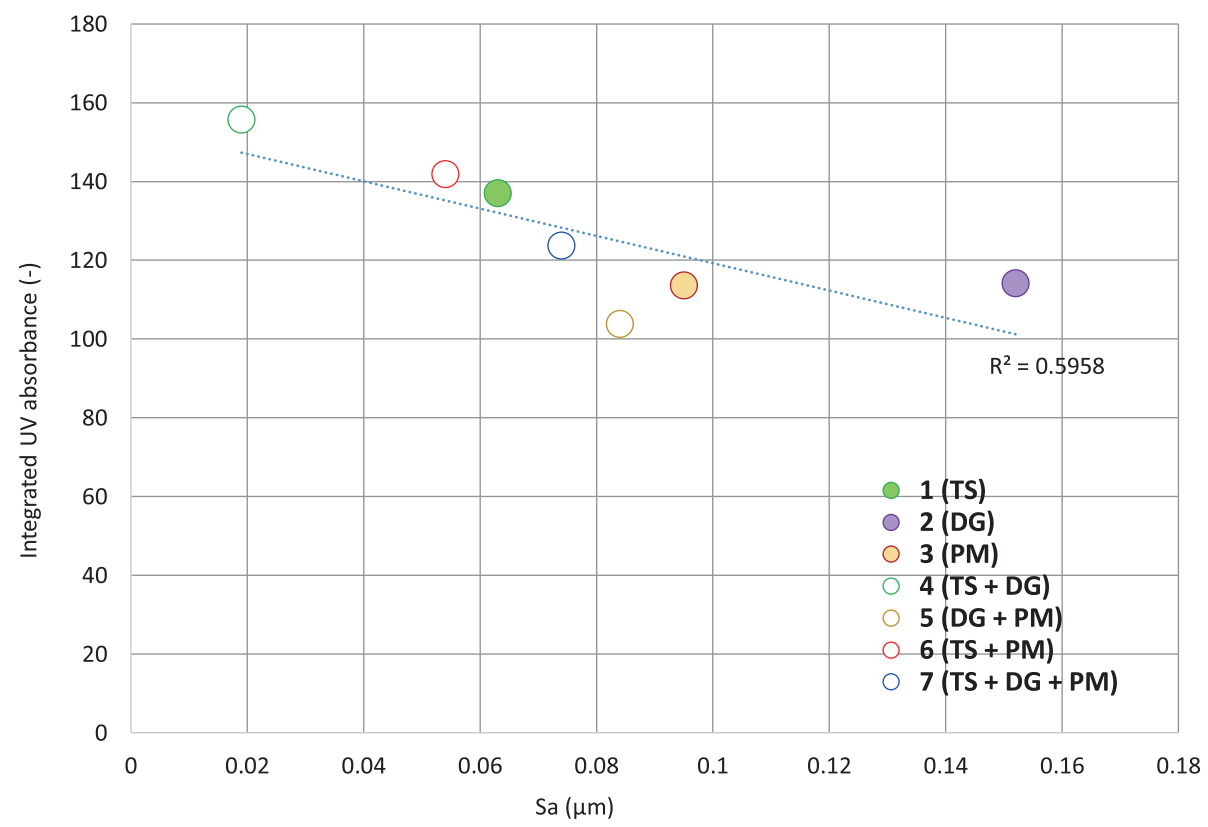

Fig. 5 Correlation between UV absorbance and surface roughness of the applied sample layer.

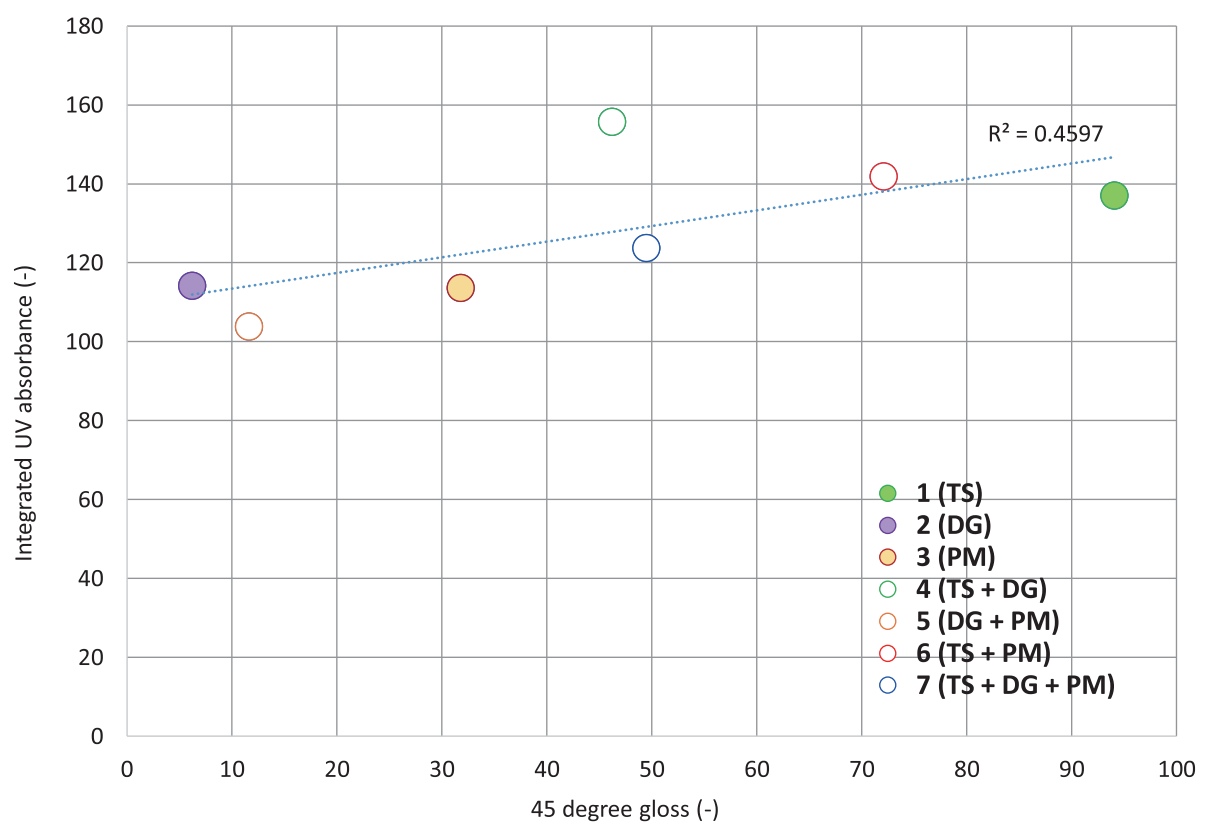

Fig. 6 Correlation between UV absorbance and 45 degree gloss of the applied sample layer.

stances, called surface treatment agents, with the powder particles to impart various properties to the pigment. However, the condition of the surface treatment agent molecule is not clearly understood after it bonds chemically to the powder surface. Therefore, HLB was mentioned as a proposal considering the interaction between each surface treatment agent group and solvent. HLB is a parameter that is frequently used to indicate the improvement in emulsion stability ${ }^{18)}$. Emulsion stability is usually considered under various solvent conditions, and the conditions are like those adopted in this study.
Each surface treatment agent forms a chemical bond with the pigment surface. Consequently, the HLB of any treatment agent should change from its original value after the treatment process. For example, triethoxy (octyl) silane is a well-known surface-treatment agent that forms a chemical bond between its ethoxy site and the target surface hydroxy site through dehydration condensation. As a result, the triethoxy (octyl) silane original HLB changed after the treatment process. We assumed that the pseudoHLB of the powder surface is a potential parameter that affects the pigment alignment. We then calculated the the- 
Table 2 Calculation of pseudo-HLB of each single surface treated nano-sized titanium dioxide powder corresponding to the mixing ratio for the preparation.

\begin{tabular}{|c|c|c|c|c|}
\hline Sample & $\begin{array}{l}\text { Surface } \\
\text { treating } \\
\text { agent }\end{array}$ & $\begin{array}{l}\text { Hydrophilic group } \\
\text { (Molecular weight) }\end{array}$ & $\begin{array}{l}\text { Hydrophobic group } \\
\text { (Molecular weight) }\end{array}$ & Calculation of pseudo-HLB \\
\hline 1 & $\begin{array}{c}\text { TS } \\
(3.00 \%)\end{array}$ & $-\mathrm{O}_{3}-\mathrm{Si}-(80)$ & $-\left(\mathrm{CH}_{2}\right) 7-\mathrm{CH}_{3}$ & $20 \times 80 /(80+113)=8.29$ \\
\hline 2 & $\begin{array}{c}\text { DG } \\
(3.00 \%)\end{array}$ & $2 x-\mathrm{COO}^{-}(88)$ & $\begin{array}{c}-\left(\mathrm{CH}_{2}\right)_{17-} \mathrm{CH}_{3}(253) \\
-\mathrm{NH}-\mathrm{CO}-(43) \\
-\mathrm{H}(1) \\
-\left(\mathrm{CH}_{2}\right)_{2}-(28)\end{array}$ & $20 \times 88 /(253+43+1+28+88)=4.26$ \\
\hline 3 & $\begin{array}{c}\text { PM } \\
(3.00 \%)\end{array}$ & $-\mathrm{COO}^{-}(44)$ & $-\left(\mathrm{CH}_{2}\right)_{12}-\mathrm{CH}_{3}(183)$ & $20 \times 44 /(44+183)=3.87$ \\
\hline
\end{tabular}

Table 3 Calculation of pseudo-HLB of each double and triple surface treated nano-sized titanium dioxide powders corresponding to the mixing ratio for the preparation.

\begin{tabular}{ccc}
\hline Sample & Surface treating agent & Calculation of pseudo-HLB \\
\hline $\mathbf{4}$ & TS $(1.50 \%)+$ DG $(1.50 \%)$ & $(8.29+4.26) / 2=\mathbf{6 . 2 8}$ \\
$\mathbf{5}$ & DG $(1.50 \%)+$ PM $(1.50 \%)$ & $(4.26+3.87) / 2=4.07$ \\
$\mathbf{6}$ & TS $(1.50 \%)+$ PM $(1.50 \%)$ & $(8.29+3.87) / 2=6.08$ \\
7 & TS $(1.50 \%)+$ DG $(1.50 \%)+$ PM $(1.50 \%)$ & $(8.29+4.26+3.87) / 3=5.47$ \\
\hline
\end{tabular}

Table 4 Surface treatment of the nano-sized titanium dioxide powders to adjust the pseudo-HLB to around 6.3 by changing the mixing ratio of each treating agent.

\begin{tabular}{ccc}
\hline Sample & Surface treating agent & Calculation of pseudo-HLB \\
\hline $\mathbf{8}$ & TS $(1.63 \%)+$ PM $(1.37 \%)$ & $(8.29 \times 1.63+3.87 \times 1.37) / 2=\mathbf{6 . 2 7}$ \\
$\mathbf{9}$ & TS $(1.58 \%)+$ DG $(0.71 \%)+$ PM $(0.71 \%)$ & $(8.29 \times 1.58+4.26 \times 0.71+3.87 \times 0.71) / 3=\mathbf{6 . 2 9}$ \\
\hline
\end{tabular}

oretical pseudo-HLB value using Griffin's equation ${ }^{19,20)}$ (Table 2). Some surface treatment agents may cause steric hindrance due to their structure, which may affect the interaction between the powders, but the surface treatment agent used in this study was not bulky and so, the influence should not be considerable.

The results suggested that the optimum HLB for uniform particle alignment was approximately 6.3. Only samples 6 and 7 exhibited the optimum pseudo-HLB value of 6.3 among the surface treatment combinations listed in Tables 2 and 3. Two new surface-treated nano-sized titanium dioxide powders, samples 8 and 9, were prepared by changing the ratio alone, without changing the total material quantity, and adjusting the pseudo-HLB value to approximately 6.3 (Table 4). The UV absorbance and surface condition of the finished coating layer prepared by the oil dispersion of new surface-treated powders were confirmed using the same method as described above. Laser micro- scope observation revealed that applied layer of sample 8 and 9 exhibited a low Sa value similar to that of sample 4 having the pseudo-HLB of 6.28 (Fig. 6). This indicates that both the coating layer surfaces were smoother than the sample layers before the pseudo-HLB was adjusted. The UV absorbance of both the applied layers of samples 8 and 9 was found to be improved from those of samples 6 and 7 (Figs. 7 and 8). Thus, their UV shielding ability was the same as that of sample 4 . The results show that the pseudo-HLB-adjusted nanosized titanium dioxide powder results in a more uniform alignment(Fig. 9).

\section{Conclusion}

In this study, surface treatments were applied to nanosized titanium dioxide powder using triethoxy (octyl) silane, disodium N-(1-oxooctadecyl)-L-glutamate, and po- 
8 (TS+PM)

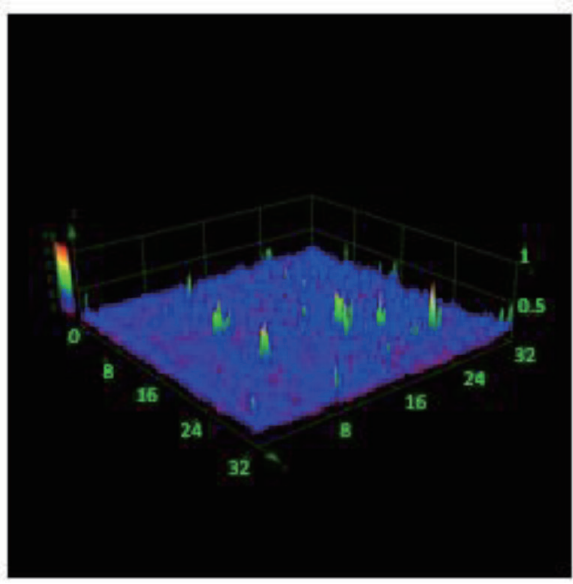

$S a=0.036 \mu \mathrm{m}, S q=0.047 \mu \mathrm{m}$
9 (TS+DG+PM)

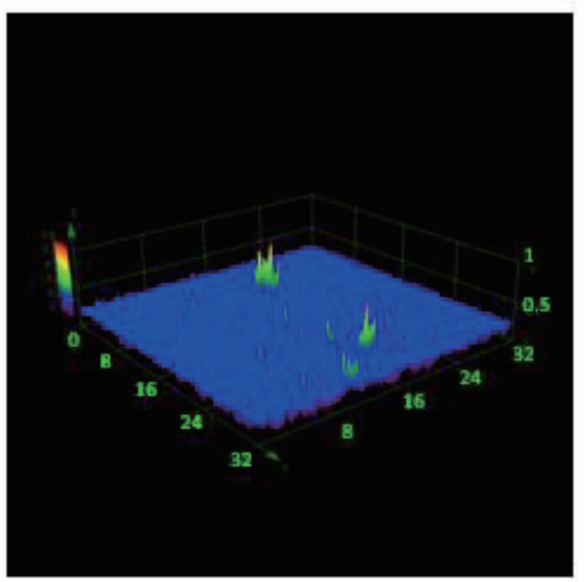

$S a=0.025 \mu \mathrm{m}, S q=0.038 \mu \mathrm{m}$

Fig. 7 Laser microscope images and values of Sa and Sq of the sample layer prepared by applying the oil dispersion of the surface treated powders fabricated to adjust the pseudo-HLB at around 6.3. (Scale unit: $\mu \mathrm{m})$.

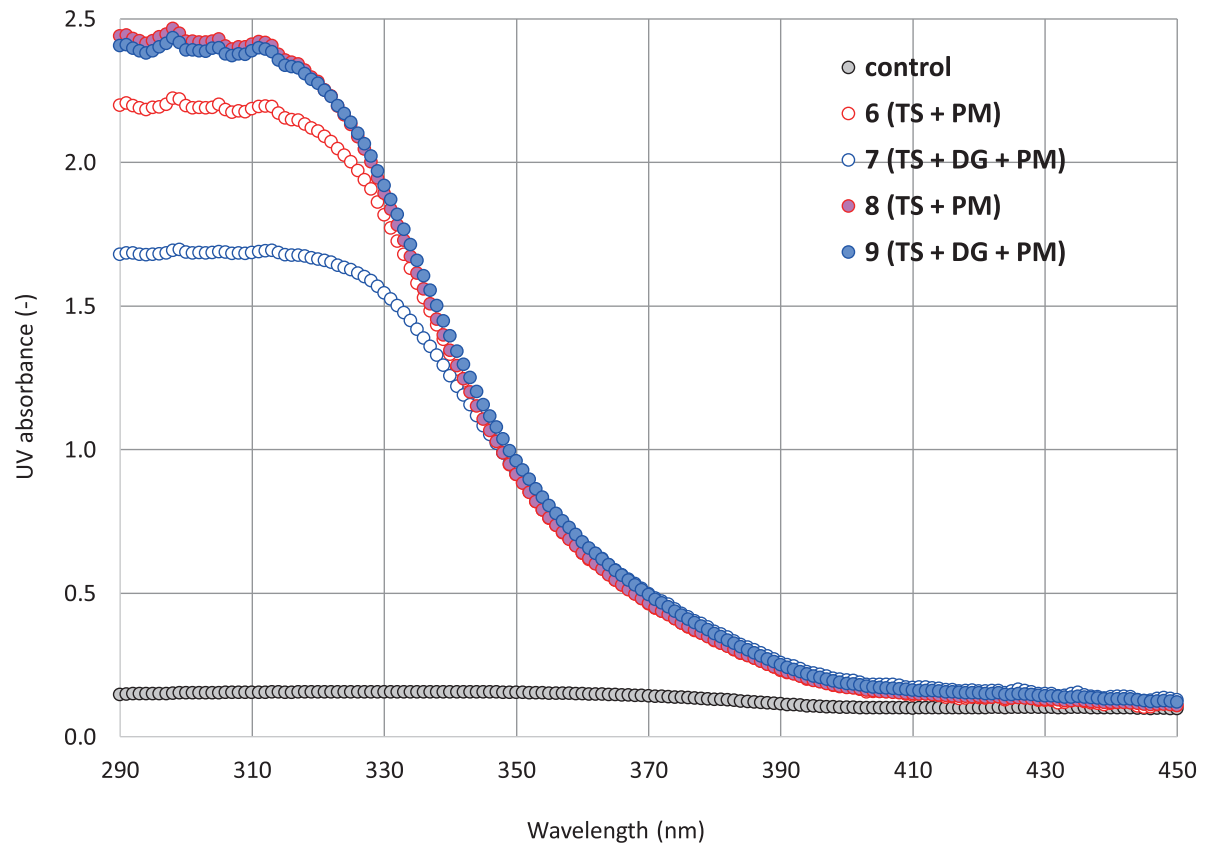

Fig. 8 Influence of the pseudo-HLB of surface treatment of powders onto the UV shielding ability of the applied layer. Sample integrated UV absorbance: $6: 141.9 \rightarrow 8: 150.5,7: 123.7 \rightarrow 9: 152.7$.

tassium myristate as treatment agents. Dispersions of treated and untreated powders were prepared and applied to a cellulose triacetate film. The surface structures of the applied layers were observed, and their UV shielding abilities were evaluated. All the treatments enhanced the flatness of the applied layer as well as their UV shielding ability. To analyze the optimal surface treatment conditions of powders that form a smooth and flat applied layer, a new parameter called the pseudo-HLB was calculated. The best flatness and UV shielding ability of the sample applied layer were obtained when the treated powders had a pseudoHLB value of approximately 6.3. This study has the potential to be applied to several industries, such as paints and cosmetics that use powders as raw materials. 


\section{S. Takekawa, M. Ohara, T. Banno et al.}

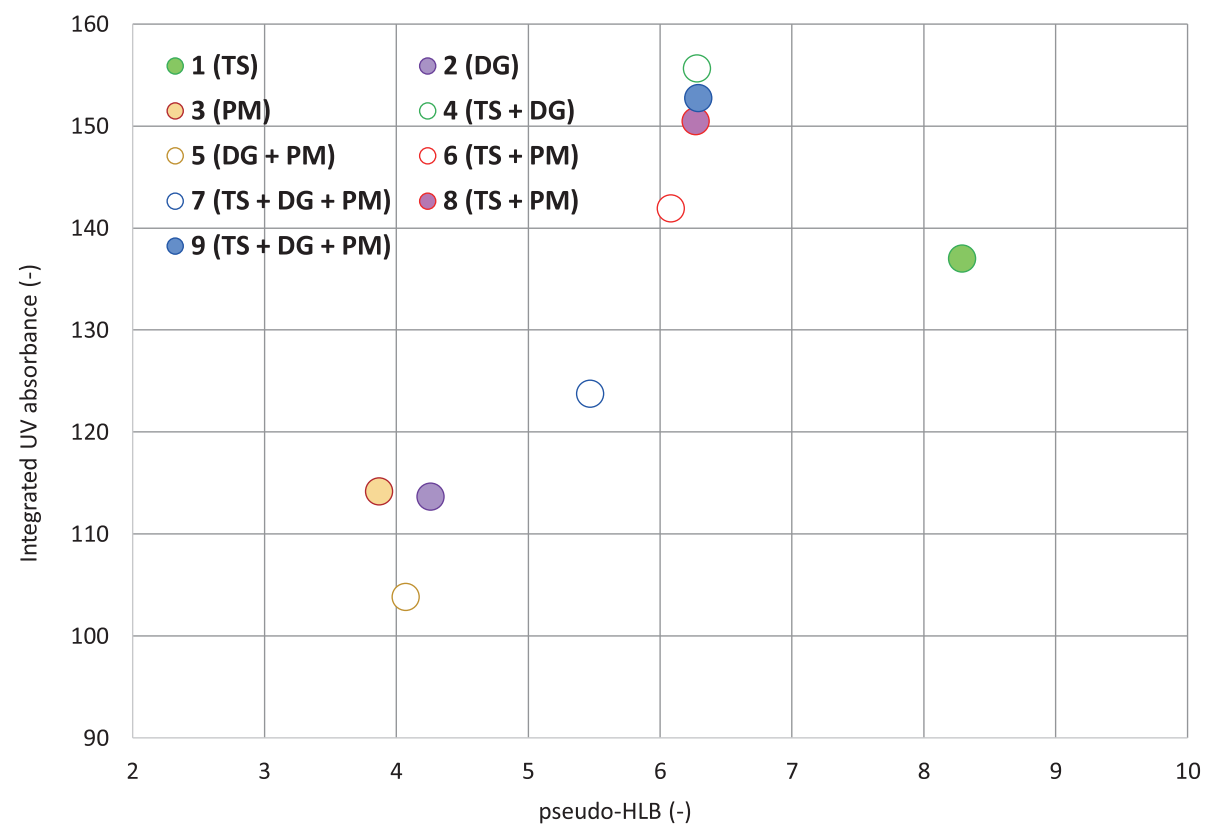

Fig. 9 Correlation between the pseudo-HLB of surface treatment powders and UV shielding ability of the applied layer of surface treated nano-sized titanium dioxide powders.

\section{Contributions}

S.T., T.B. and K.A. were involved in study design and data interpretation.

S.T. and M.O. were involved in the data analysis.

All authors revised and commented the manuscript, and approved final report.

\section{References}

1) Schueller, R.; Romanovski, P. Formulating Cosmetics Emulsion, Beginning Cosmetic Chemistry. $3^{\text {rd }}$ ed. Allured Pub Corp, Carol Stream IL, Chap. 25, pp. 237240 (2009).

2) Schueller, R.; Romanovski, P. Creating Colorful Cosmetics, Beginning Cosmetic Chemistry. $3^{\text {rd }}$ ed. Allured Pub Corp, Carol Stream IL, Chap. 15, pp. 147157 (2009).

3) Cira, N.; Benusiglio, A.; Prakash, M. Vapour-mediated sensing and motility in two-component droplets. $\mathrm{Na}$ ture 519, 446-450 (2015).

4) Kim, H.; Boulogne, F.; Um, E.; Jacobi, I.; Button, E.; Stone, H. Controlled uniform coating from the interplay of Marangoni flows and surface-adsorbed macromolecules. Phys. Rev. Lett. 116, 124501 (2016).

5) Soulie, V.; Karpitschka, S.; Lequien, F.; Prene, P.; Zemb, T.; Möhwald, H.; Riegler, H. The evaporation behavior of sessile droplets from aqueous saline solutions. Phys. Chem. Chem. Phys. 17, 22296 (2015).

6) Karpitschka, S.; Liebig, F.; Riegler, H. Marangoni contraction of evaporating sessile droplets of binary mix- tures. Launguir 33, 4682-4687 (2017).

7) Sadafi, H.; Dehaeck, S.; Rednikov, A.; Colinet, P. Vapormediated versus substrate-mediated interactions between volatile droplets. Langmuir 35, 7060-7065 (2019).

8) Marin, A.; Gelderblom, H.; Lohse, D.; Snoeijer, J. Order-to-disorder transition in ring-shaped colloidal stains. Phys. Rev. Lett. 107, 085502 (2011).

9) Yunker, P.; Still, T.; Lohr, M.; Yodh, A.G. Suppression of the coffee-ring effect by shape-dependent capillary interactions. Nature 476, 308-311(2011).

10) De Polo, K.F. Sunscreen. in A Short Textbook of Cosmetology, Chap. 3, pp.86-133 (1998).

11) Rosca, I.D.; Watari, F.; Uo, M. Microparticle formation and its mechanism in single and double emulsion solvent evaporation. J. Control. Release 99, 271-280 (2004).

12) Schueller, R.; Romanovski, P. Laboratory batching of cosmetics products. in Beginning Cosmetic Chemistry. $3^{\text {rd }}$ ed. Allured Pub Corp, Carol Stream IL, Chap. 23, pp. 225-230 (2009).

13) Edwin, P. Chemistry of silane coupling agents. in Silane Coupling Agents. $2^{\text {nd }}$ ed. Chap. 2, pp. 31-54 (1991).

14) Miyoshi, R. US Pat. 4606914A (1982).

15) Fujikake, K.; Tago, S.; Plasson, R.; Nakazawa, R.; Okano, K.; Maezawa, D.; Mukawa, T.; Kuroda, A.; Asakura, K. Problems of in vitro SPF measurements brought about by viscous fingering generated during sunscreen applications. Skin Pharmacol. Physiol. 27, 254-262 (2014). 
16) Wakabayashi, M.; Okano, K.; Mukawa, T.; Maezawa, D.; Masaki, H.; Kuroda, A.; Asakura, K. Problems on the evaluation of the critical wavelength of sunscreens for "Broad Spectrum" approval brought on by viscous fingering during sunscreen application. Photochem. Photobiol. 92, 637-643 (2016).

17) Binks, B.; Brown, J.; Fletcher, P.; Johnson, A.; Marinopoulos, I.; Crowther, J.; Thompson, M. Evaporation of sunscreen films: How the UV protection properties change. ACS Appl. Mater. Interfaces 8, 13270-13281 (2016).

18) Owens, D.K.; Wendt, R.C. Estimation of the surface free energy of polymers. J. Appl. Polym. Sci. 13, 1741-1747(1969).

19) Griffin, W.C. Classification of surface-active agents by HLB. J. Soc. Cosmet. Chem. 1, 311-326(1946).

20) Griffin, W.C. Calculation of HLB values of non-ionic surfactants. J. Soc. Cosmet. Chem. 5, 249-255 (1954). 